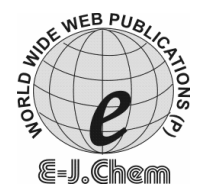

http://www.e-journals.net
ISSN: 0973-4945; CODEN ECJHAO

E-Journal of Chemistry

2009, 6(S1), S59- S64

\title{
Analysis of Nabumetone in Bulk and Tablet Formulation by a New and Validated Reverse Phase High Performance Liquid Chromatography
}

\author{
PRAFULLA KUMAR SAHU* and M. MATHRUSRI ANNAPURNA \\ Department of Pharmaceutical Analysis \& Quality Assurance, \\ Roland Institute of Pharmaceutical Sciences, Berhampur, Orissa, India. \\ *Gayatri Institute of Pharmaceutical Science and Technology, \\ Gunupur, Rayagada, Orissa, India. \\ kunasahu1@ rediffmail.com
}

Received 8 January 2009; Accepted 8 March 2009

\begin{abstract}
RP-HPLC analytical method for the estimation of nabumetone in pharmaceutical dosage forms was developed and validated. A Hypersil ODS C18, $4.6 \mathrm{~mm} \times 250 \mathrm{~mm}, 5 \mu \mathrm{m}$ column from Supelco (India), with mobile phase comprised of acetonitrile: triple distilled water (50:50) with a total run time of 18 min was used and the wavelength of the detector was set at $230 \mathrm{~nm}$. Stavudin is used as internal standard. The retention times were $14.167 \mathrm{~min}$ and $1.967 \mathrm{~min}$ for nabumetone and stavudin (IS) respectively. The extraction recovery of nabumetone from pharmaceutical dosage form (tablets) was $>101 \%$ and the calibration curve was linear $\left(r^{2}=0.995\right)$ over nabumetone concentrations ranging from 1 to $200 \mu \mathrm{g} / \mathrm{mL}$. The method had an accuracy of $>99 \%$ and LOD and LOQ of $0.17482 \mu \mathrm{g} / \mathrm{mL}$ and 0.5827 $\mu \mathrm{g} / \mathrm{mL}$ respectively. The method reported is simple, reliable, precise and accurate and has the capability of being used for determination of nabumetone in bulk and pharmaceutical dosage forms.
\end{abstract}

Keywords: Nabumetone, Non-steroidal anti-inflammatory drug, RP-HPLC.

\section{Introduction}

Nabumetone (Figure 1) is a non acidic NSAID (Non-steroidal anti-inflammatory drug) that is rapidly metabolized in the liver to a major active metabolite, 6-methoxy-2-naphthyl acetic acid. As found with previous NSAIDs, nabumetone's active metabolite inhibits the cyclooxygenase enzyme preferentially blocks cyclo-oxygenase- 2 activity which is indirectly responsible for the production of inflammation and pain during arthritis by way of enhancing the production of endoperoxides and prostaglandins E2 and I2 (prostacyclin). The active metabolite of nabumetone 
is felt to be the compound primarily responsible for therapeutic effect. Comparatively, the parent drug is a poor inhibitor of prostaglandin synthesis. It may be less nephrotoxic than indomethacin which decreases the excretion of 6-oxo-PGF $\mathrm{PG}_{1 \mathrm{a}}$ by inhibition of cyclooxygenase- 1 or by inhibition of specific exercise-induced activation of cyclo-oxygenase- 2 , or both ${ }^{1}$. Nabumetone belongs to a new class of NSAID with a low potential for causing gastrointestinal mucosal irritancy and inhibition of platelet function ${ }^{2}$ and has little effect on renal prostaglandin secretion and had less of an association with CHF (congestive heart failure) than other traditional drugs of the class ${ }^{3}$. Effects of nabumetone on blood pressure control in hypertensive patients on ACE inhibitors is also good i.e. equivalent to paracetamol $^{4}$.

There are few papers published reporting analytical methods ${ }^{5}$ for nabumetone. Two of them employed HPLC with UV-detection ${ }^{6,7}$. One HPLC method using direct injection on restricted access media columns ${ }^{8}$. Flow injection analysis (FIA) with UV-detection was also reported for the determination of nabumetone in pharmaceutical preparations ${ }^{9}$. Three methods using HPLC with fluorescence detection ${ }^{10-13}$ were reported. M. Nobilis et al. ${ }^{12}$ carried out biotransformation and disposition studies in humans and minipigs using HPLC with UV, fluorescence and mass spectrometric detection. The interactions with $\gamma$-cyclodextrin were also studied by fluorescence measurements ${ }^{13}$. Two methods employed HPLC using photodiode array (PDA) detector ${ }^{14-15}$ and mass spectrometric detection ${ }^{15}$ for the determination of nabumetone and its metabolites. Murillo Pulgarín et al. ${ }^{16-18}$ reported three analytical methods using different techniques along with phosphorescence. Liquid chromatography methods using different techniques of mass spectrometry were also reported $^{19-21}$. The electrochemical behavior of nabumetone by a voltammetric technique ${ }^{22}$ and a novel colorimetric method based on chemical derivatization ${ }^{23}$ were also published.

We here present a new method for the determination of nabumetone in bulk and pharmaceutical dosage forms which utilizes a very cheap solvent system on a Hypersil ODS C18 analytical column. This type of method leads to better retention, very sharp and symmetrical peak shapes and exhibits a very good selectivity for nabumetone.<smiles>COc1ccc2cc(CCC(C)=O)ccc2c1</smiles>

\section{Experimental}

Figure 1. Chemical structure of nabumetone.

\section{Instrumentation}

Quantitative HPLC was performed on a binary gradient HPLC with Shimadzu LC10AT and LC10AT VP series HPLC pumps, with a $20 \mu \mathrm{L}$ Injection of sample loop (manual), and SPD 10A VP UV-Visible Detector. The output signal was monitored and integrated using Shimadzu CLASS-VP Version 6.12 SP1 software. Hypersil ODS C18 (46 mm X $25 \mathrm{~cm}, 5$ $\mathrm{mm}$ ) column was used for the separation.

\section{Standards and chemicals}

Nabumetone and stavudin were gifts obtained from Aurobindo pharma (Hyderabad, India). Niltis tablets (IPCA) containing $250 \mathrm{mg}$ and $500 \mathrm{mg}$ of nabumetone, were purchased from local market. Acetonitrile of HPLC grade was purchased from Burdick and Jackson (Muskagon, MI, USA). 


\section{Preparation of standard drug solutions}

$10 \mathrm{mg}$ each of nabumetone and stavudin (IS) were accurately weighed and transferred into two separate $10 \mathrm{~mL}$ of volumetric flask containing $5 \mathrm{~mL}$ of mobile phase sonicated for 10 minutes, diluted with mobile phase up to the mark and filtered through $0.45 \mu$ membrane to get this stock solution $(1 \mathrm{mg} / \mathrm{mL})$.

\section{Chromatographic conditions}

The mobile phase used in this study was a mixture of acetonitrile and triple distilled water 50:50 v/v. Then the content was sonicated for 30 minutes for degassing purpose and then filtered through $0.45 \mu \mathrm{m}$ (pore diameter) Whattman filter paper. The mobile phase was pumped from the solvent reservoir to the column at a flow rate of $1.0 \mathrm{~mL} / \mathrm{min}$. The eluents were monitored at $230 \mathrm{~nm}$. The column temperature was maintained ambient through out the experiment.

\section{Calibration of standards:}

Calibration standards were prepared by spiking working standard solutions into methanol containing $5 \mathrm{~mL}$ volumetric flasks to yield concentrations of $1,2,5,10,20,40,50,100$, 120, 140 and $200 \mu \mathrm{g} / \mathrm{mL}$. To the above solutions $20 \mu \mathrm{g} / \mathrm{mL}$ of stavudin (Internal Standard) was added and the final volume was made up to the mark. The represented data was shown in Table 1. A $20 \mu \mathrm{L}$ aliquot was injected in to the analytical column. The resultant peak areas of the drug and internal standard were measured. Calibration curve was plotted between peak area ratios of drug and internal standard against concentration of the drug.

Table 1. Linearity range of nabumetone.

\begin{tabular}{ccc}
\hline $\begin{array}{c}\text { Concentration } \\
\mu \mathrm{g} / \mathrm{mL}\end{array}$ & $\begin{array}{c}\text { Peak area ratio } \\
\text { (Drug / I.S.) }\end{array}$ & Statistical Analysis \\
\hline 1 & 1.3774 & \\
2 & 3.2013 & Slope (a) 1.53798 \\
5 & 8.0034 & \\
10 & 16.0067 & \\
20 & 32.6745 & Intercept (b) 1.93003 \\
40 & 66.4828 & \\
50 & 80.0334 & \\
100 & 157.0103 & \\
120 & 190.2207 & Correlation coefficient 0.9995 \\
140 & 221.3511 & \\
200 & 303.0021 & \\
\hline
\end{tabular}

\section{Recovery of nabumetone in tablets}

20 Tablets were weighed, finely powdered and an accurately weighed sample of powdered tablets equivalent to $25 \mathrm{mg}$ of nabumetone was extracted with acetonitrile in a $25 \mathrm{~mL}$ volumetric flask using ultra sonicator. This solution was filtered through Whatmann No 1 filter paper. The solution obtained was diluted with the mobile phase so as to obtain a concentration in the range of linearity previously determined. An aliquot $(20 \mu \mathrm{g} / \mathrm{mL})$ of the internal standard was added to the sample solution prior to the dilution. All determinations were carried out in six replicates. The represented data was shown in Table 2. 
Table 2. Amount of nabumetone in tablet dosage forms by the HPLC method.

\begin{tabular}{ccccc}
\hline $\begin{array}{c}\text { Formulation Br.: } \\
\text { Niltis tablets (IPCA) }\end{array}$ & $\begin{array}{c}\text { Labeled } \\
\text { amount in mg. }\end{array}$ & $\begin{array}{c}\text { Amount recovered } \\
\text { in mg. }(\mathrm{n}=6) \text { Mean } \pm \text { S.D }\end{array}$ & $\% \mathrm{CV}$ & $\begin{array}{c}\% \\
\text { Recovery }\end{array}$ \\
\hline $250 \mathrm{mg}$ Tablet & 250 & $249.5 \pm 0.10$ & \pm 0.042 & 99.8 \\
$500 \mathrm{mg}$ Tablet & 500 & $505.3 \pm 0.278$ & \pm 0.195 & 101.06 \\
\hline
\end{tabular}

\section{Results and Discussion}

\section{Method validation}

Specificity and selectivity of the method was assessed by preparing a drug concentration of $100 \mu \mathrm{g} / \mathrm{mL}$ from pure drug stock and commercial sample stock in selected mobile phase and analyzed. The Figure 2 shows that nabumetone is clearly separated from its internal standard and these are well separated from each other. The HPLC chromatograms recorded for the drug-matrix (mixture of the drug-excipients) showed almost no peaks within a retention time range of $18 \mathrm{~min}$ (Figure 3). Thus, the HPLC method presented in this study is selective for nabumetone. The method is linear in the concentration range of $1-200 \mu \mathrm{g} / \mathrm{mL}$. Intra-day and inter-day precision was studied by six replicate measurements at three concentration levels over a period of 3 consecutive days. Accuracy of the method was determined by calculating recovery studies. Statistical evaluation revealed that relative standard deviation of the drug at different concentration levels for six injections was less than 0.111. Precision and accuracy data were shown in Table $3 \& 4$ respectively. For system suitability, six replicates of standard sample were injected and different parameters were studied (Table 5). The tailing factor for nabumetone was always less than 2.0.

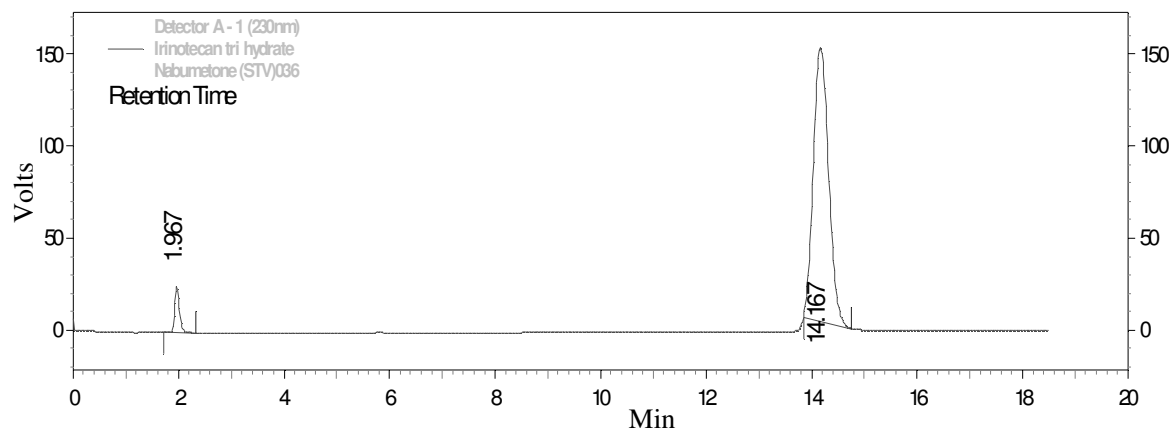

Figure 2. Chromatogram of nabumetone (Standard).

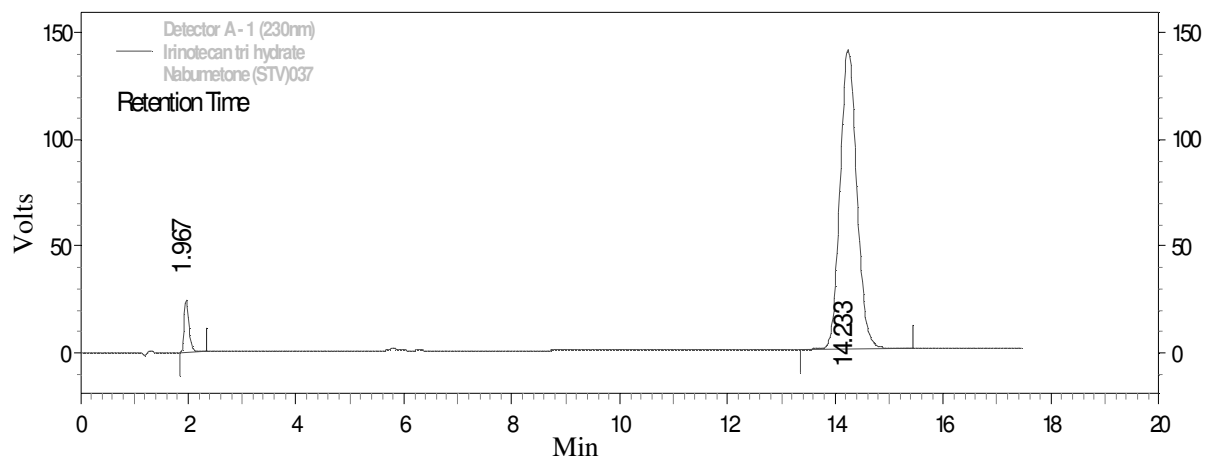

Figure 3. Chromatogram of nabumetone (Formulation). 


\begin{tabular}{cccc}
\hline Figure No. & Name of the Peaks & RT, min. (Standard) & RT, min. (Formulation) \\
\hline 2 & Stavudine & 1.967 & 1.967 \\
3 & Nabumetone & 14.167 & 14.233 \\
\hline
\end{tabular}

Table 3. Precision studies.

\begin{tabular}{ccc}
\hline $\begin{array}{c}\text { Concentration } \\
\mu \mathrm{g} / \mathrm{mL}\end{array}$ & $\begin{array}{c}\text { Peak area } \\
\text { Ratio }\end{array}$ (drug/IS) & $\%$ RSD \\
\hline 50 & $80.06355 \pm 0.089622$ & 0.111938 \\
\hline${ }^{*}$ Each value is average of eight determinations \pm Std. Deviation
\end{tabular}

Table 4. Accuracy studies.

\begin{tabular}{ccccc}
\hline $\begin{array}{c}\text { Mixture of pure } \\
\text { and formulation }\end{array}$ & $\begin{array}{c}\text { Conc. of pure } \\
\text { drug, } \mu \mathrm{g} / \mathrm{mL}\end{array}$ & $\begin{array}{c}\text { Conc. of } \\
\text { Formulation, } \mu \mathrm{g} / \mathrm{mL}\end{array}$ & $\begin{array}{c}\% \text { Recovery* } \\
\text { of pure drug }\end{array}$ & \% RSD \\
\hline $80 \%$ & 40 & 50 & $98.29 \pm 0.1222$ & 0.1243 \\
$100 \%$ & 50 & 50 & $99.393 \pm 0.3837$ & 0.3860 \\
$120 \%$ & 60 & 50 & $101.55 \pm 0.3089$ & 0.3051 \\
\hline \multicolumn{5}{c}{ *Each value is average of three determinations \pm Std. Deviation } \\
\hline
\end{tabular}

Table 5. System suitability parameters.

\begin{tabular}{lll}
\hline S.No & \multicolumn{1}{c}{ Parameters } & \multicolumn{1}{c}{ values } \\
\hline 1. & Theoretical plates $(\mathrm{N})$ & 9765.06 \\
2. & Resolution between drug \& IS & 22.721 \\
3. & LOD,$\mu \mathrm{g} / \mathrm{mL}$ & 0.17482 \\
4. & LOQ,$\mu \mathrm{g} / \mathrm{mL}$ & 0.5827 \\
\hline
\end{tabular}

\section{Conclusion}

Under the presently prescribed conditions, the recoveries of nabumetone were found to be from 98.29 to $101.55 \%$. This indicates that commonly used excipients in pharmaceutical formulation were not interfering in the proposed method. This method is very useful for determination of nabumetone in pharmaceutical dosage forms, clinical studies and pharmacokinetic studies.

The observation of \% C.V less than 2.0 for both intra- and inter-day measurements also indicates high degree of precision. In the present method, we have established a linearity range of $1-200 \mu \mathrm{g} / \mathrm{mL}$; this linearity range covers all the strengths of nabumetone. Hence this method can be applied for quantifying the low levels of nabumetone in pharmaceutical dosage forms and other pharmacokinetic studies.

\section{References}

1. Olsen N V, Jensen N G, Hansen J M, Christensen N J, Fogh-Andersen N and Kanstrup I L, Clin Sci.,1999, 97, 457- 465.

2. Kristensen Jrgen, Viklund Andreas, Feltelius Nils and Larsson Anders, Platelets. 1996, 7, 149 - 152.

3. Donnan P T, Pharmacoepidemiol Drug Safety, 2000, 8, 115.

4. Palmer Robert H, Haig Ann E, Flavin Susan K and Iyengar Malini K, Am J Hypertens. 2001, 14, 85A.

5. Starek Małgorzata and Krzek Jan, Talanta, 2009, 77, 925-942.

6. Al-Momani Idrees F, Anal Lett., 1997, 30, 2485-2492.

7. Jang E J, Lee Y J, Park M G and Shim C K, Anal Lett., 1995, 28, 2379-2389. 
8. Haque Ahsanul and Stewart James T, Biomed Chromatogr., 1999, 13, 51-56.

9. Can N O, Tuncel M and Aboul-Enein H Y, Pharmazie., 2003, 58, 22-24.

10. Mikami E, Goto T, Ohno T, Matsumoto H and Nishida M, J Pharm Biomed Anal., 2000, 23, 917-925.

11. ska Kamila Kobyli, Ska Ma gorzata Barli and Ska Maria Kobyli, J Pharm Biomed Anal., 2003, 32, 323-328.

12. Nobilis M, Kopecký J, Tina J Kv, Svoboda Z, Pour M, Kune J, Apek M Hol and Ová L Kolá, J Pharm Biomed Anal., 2003, 32, 641-656.

13. Al-Rawashdeh A F Nathir, J Inclusion Phenomena and Macrocyclic Chem. 2005, 51(1-2), 27-32.

14. Rao R Nageswara, Meena S, Nagaraju D and Rao A Raghu Ram, Biomed Chromatogr., 2004, 19, 362-368.

15. Nobilis M, Holcapek M, Kolárová L, Kopecký J, Kunes M, Svoboda Z and Kvetina J, J Chromatogr. A, 2004, 1031, 229-236.

16. Pulgarín J A Murillo, Molina A Alañón and Pardo M T Alañón, Analytica Chimica Acta, 2005, 528, 77-82.

17. Pulgarín J A Murillo, Molina A Alañón and Pardo M T Alañón, Anal Biochem., 2005, 339, 157-164.

18. Pulgarín Jose A Murillo, Molina Aurelia Alañón and Robles Ignacio Sánchez-Ferrer, Analytica Chimica Acta. 2005, 554, 37-42.

19. Patel Bhavin N, Sharma Naveen, Sanyal Mallika, Prasad Arpana and Shrivastav Pranav S, Biomed Chromatogr., 2008, 22, 1213-1224.

20. Wolff J C, Hawtin P N, Monté S, Balogh M and Jones T, Rapid Commun Mass Spectrom., 2001, 15, 265-272.

21. Sheen J F and Her G R, Anal Bioanal Chem. 2004, 380, 7-8.

22. Altun Yuksel, Dogan Burcu, Ozkan Sibel A and Uslu Bengi, Acta Chim Slov., 2007, 54, 287-294.

23. Adegoke A O, Idowu S O and Olaniyi A A, Afr J Med Med Sci., 2007, 36, 249-257. 


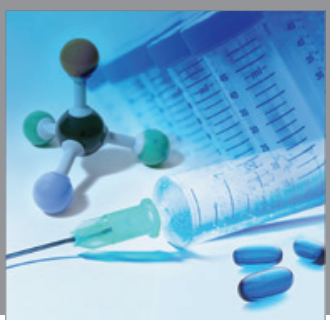

International Journal of

Medicinal Chemistry

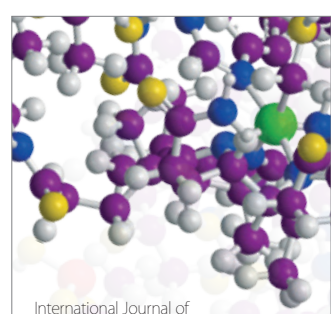

Carbohydrate Chemistry

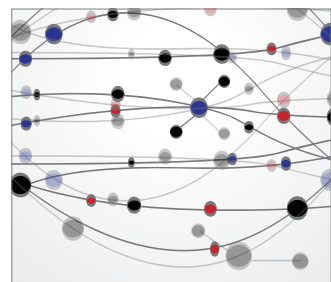

The Scientific World Journal
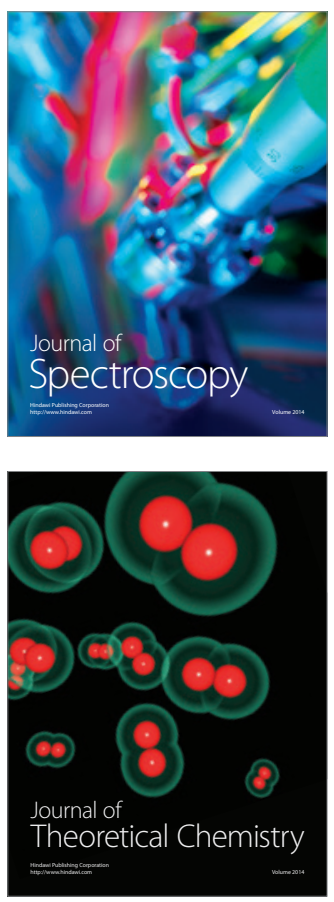
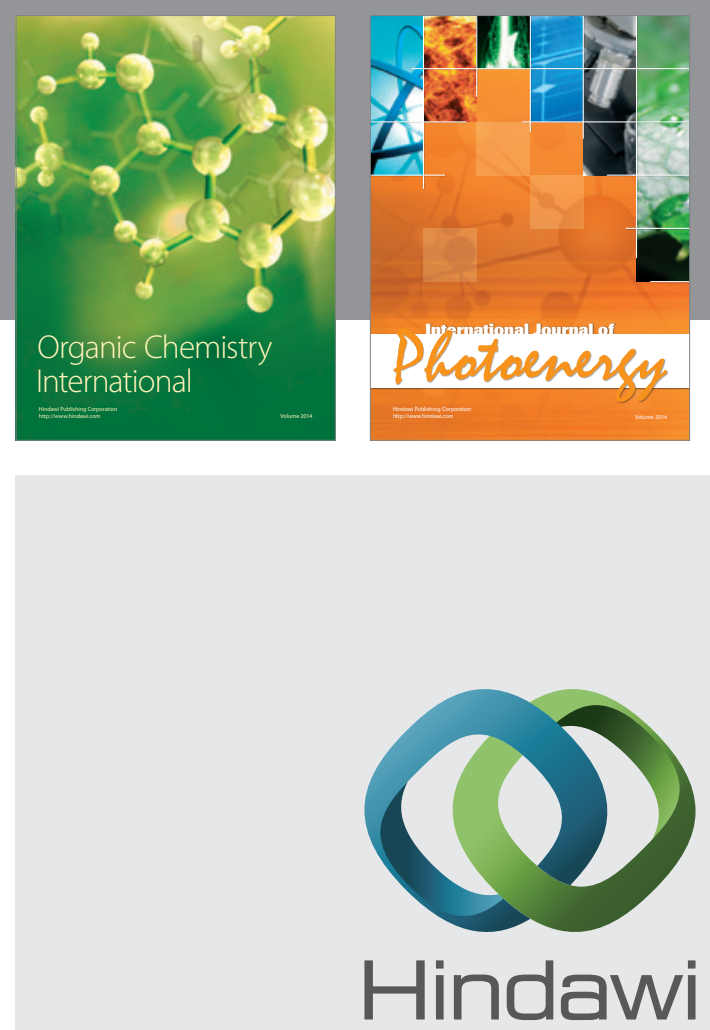

Submit your manuscripts at

http://www.hindawi.com
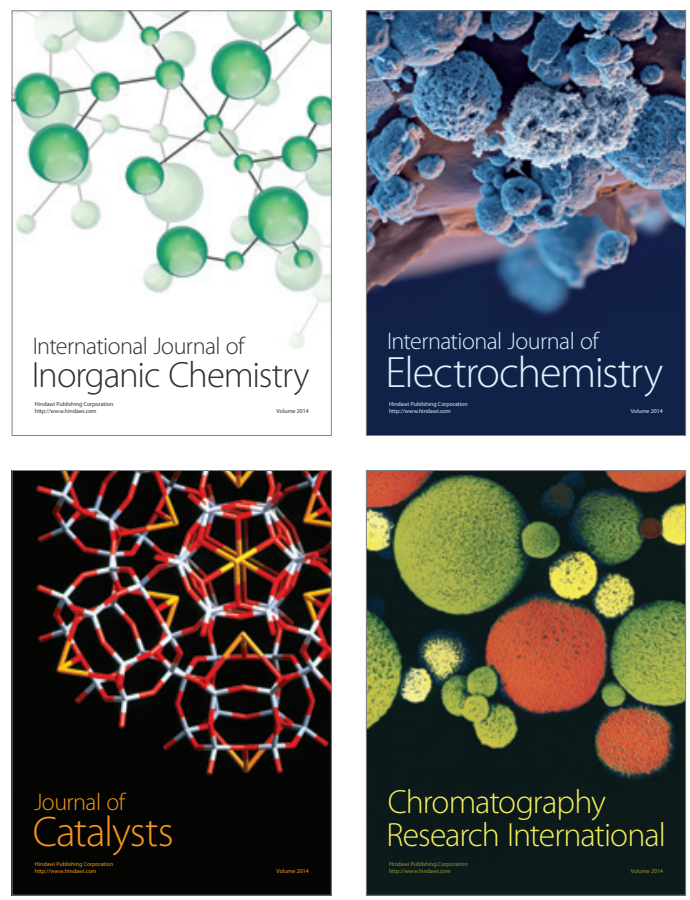
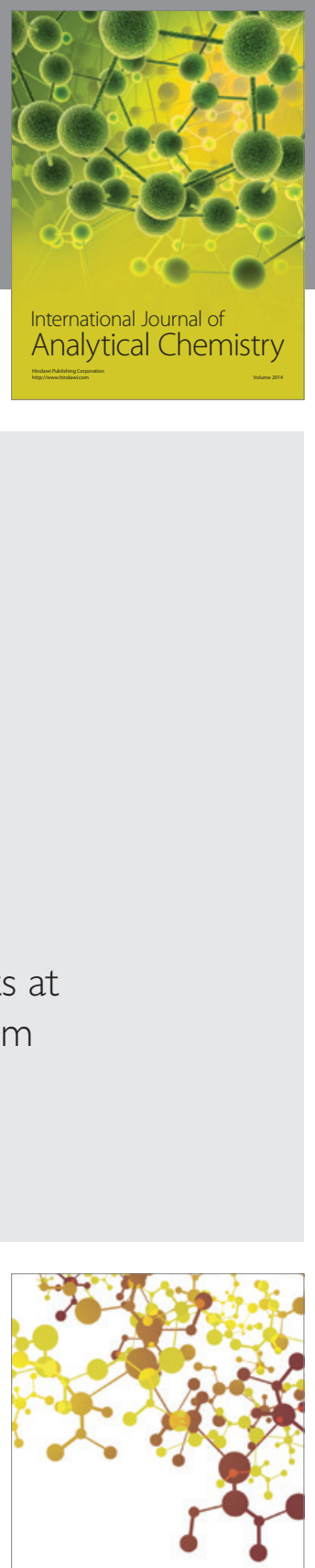

Journal of

Applied Chemistry
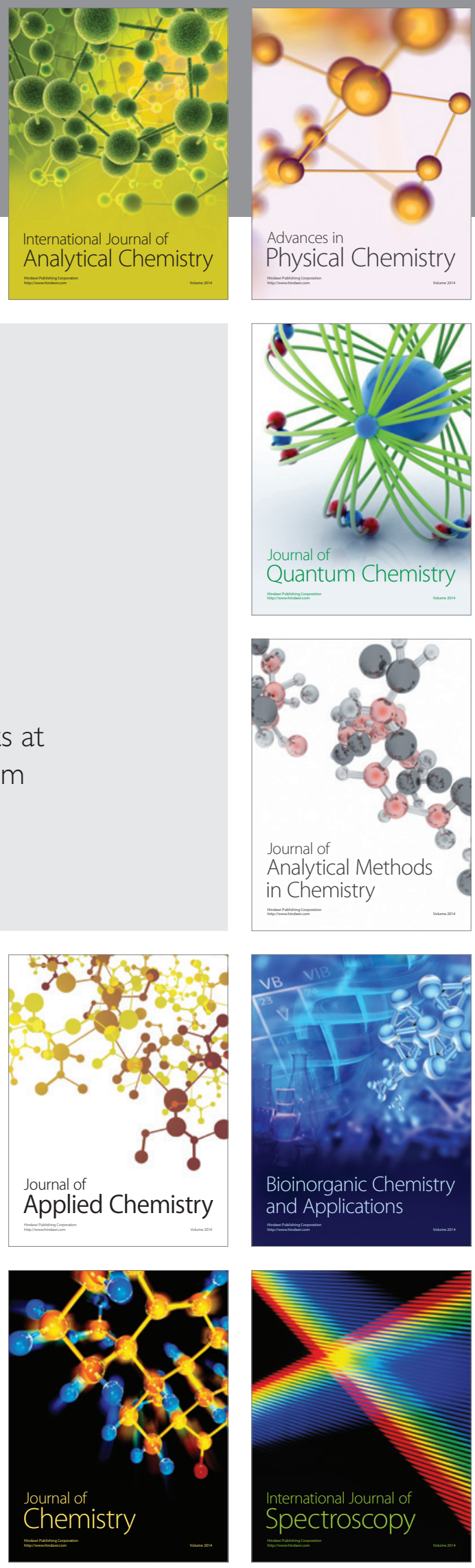